\title{
IMPLANTAÇÃO DO PROTOCOLO DE SEPSE PEDIÁTRICO EM UM HOSPITAL MUNICIPAL DE SÃO JOSÉ DOS CAMPOS: ADESÃO, ASSERTIVIDADE E IMPACTO NA MORTALIDADE
}

\author{
Renata Mantovani', Gabriela de Almeida Lemes Mari², Andrea de Fátima Cornélio², Juliane Gasetto², Carolina \\ dos Santos Scarpa ${ }^{3}$ \\ 1- Diretora de Enfermagem HMJCF, 2- Enfermeiros HMJCF, 3- Coordenadora Médica Pediatria HMJCF
} HMJCF: Hospital Municipal Dr. José de Carvalho Florence

Eixo temático: Avaliação e Qualidade do Cuidado

\section{INTRODUÇÃO}

A sepse é uma das principais causas de internação e óbito em UTI. A incidência de sepse tem aumentado na faixa pediátrica, em virtude do aumento da população de risco como recém-nascidos prematuros e a maior sobrevida de pacientes com doenças graves. Considera-se primordial $\bigcirc$ reconhecimento precoce dos sinais para uma melhora da sobrevida. Nessa perspectiva, foi implantado em março de 2017 o protocolo de Sepse Pediátrico no referido hospital, com objetivo de adequação da assistência padronizada a todas as crianças com quadro de SIRS, sepse e choque séptico.

\section{OBJETIVO}

Avaliar a adesão e assertividade do protocolo e verificar os dados de mortalidade após implantação do protocolo.

\section{METODOLOGIA}

Trata-se de um estudo descritivo, retrospectivo, com abordagem quantitativa, realizado por meio de levantamento do banco de dados de auditoria, no período de outubro de 2016 a outubro de 2018.

\section{RESULTADOS}

Gráfico 1 - Número absoluto de protocolos abertos e protocolos inseridos.

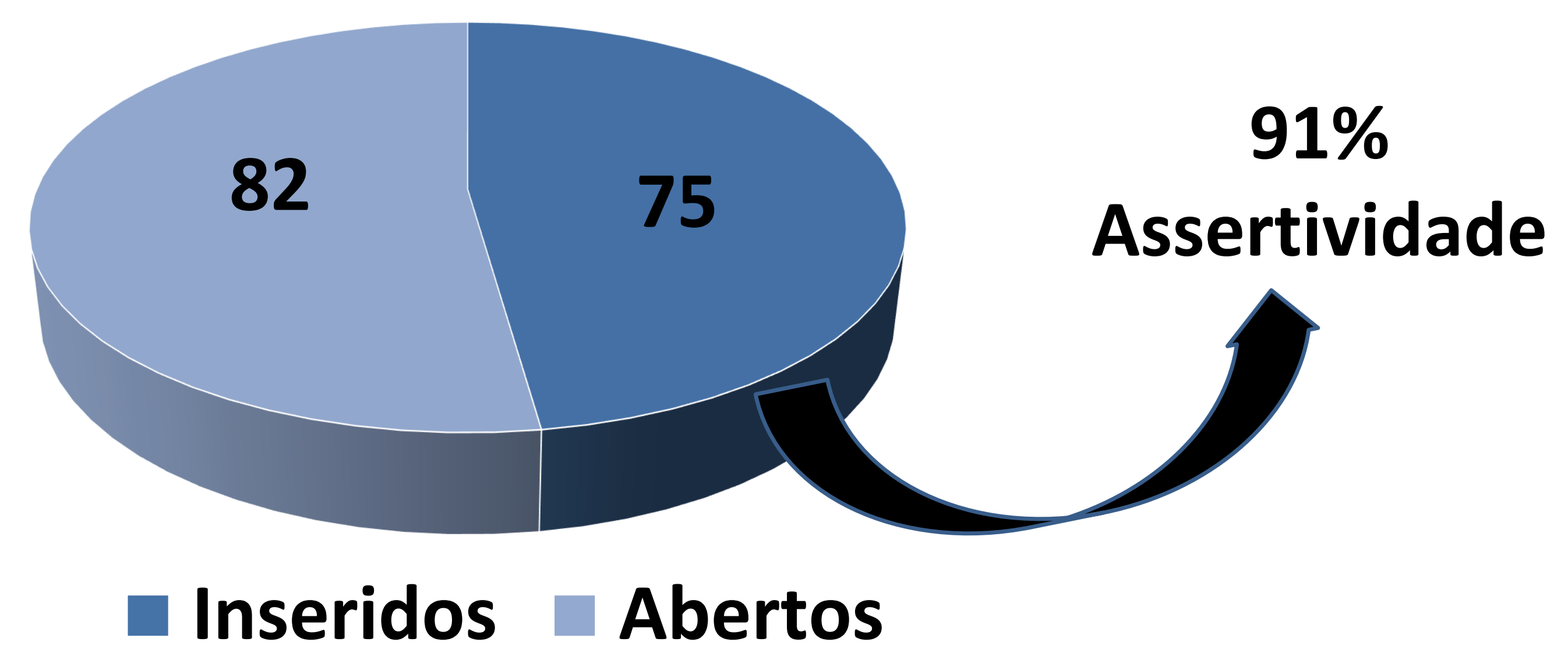

Gráfico 2 - Mortalidade por Sepse antes da implantação do protocolo e após.

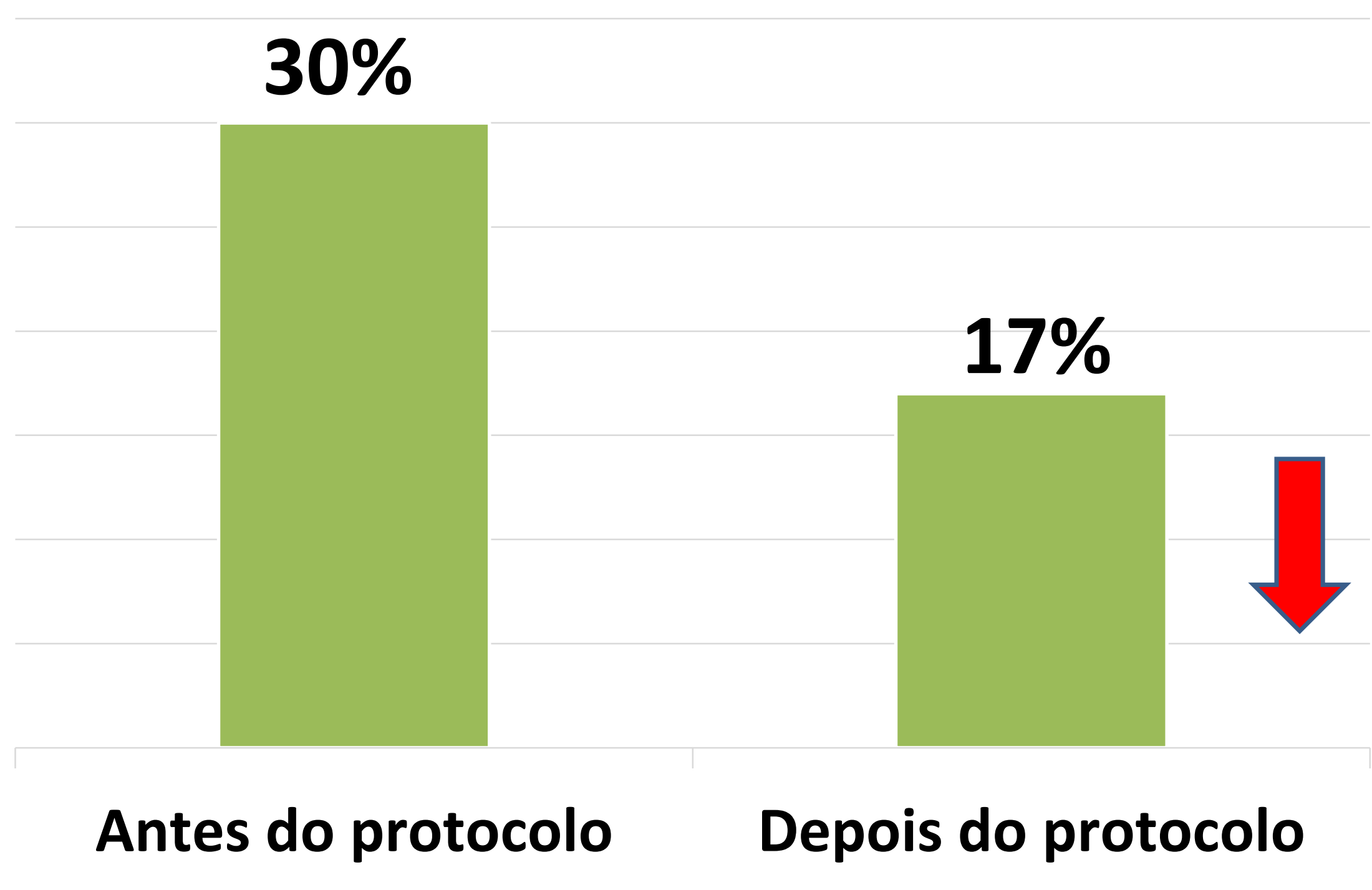

Quanto a adesão ao pacote na $1^{a}$ hora do atendimento ao paciente inserido no protocolo, obtivemos o resultado de $50 \%$ desde a implantação.

\section{CONCLUSÃO}

CONCLUSÃO: No cenário desta unidade, a implantação do protocolo de sepse pediátrico, apesar de recente, vem sendo peça chave para identificação precoce dos pacientes com sinais de SIRS e/ou disfunção orgânica, reduzindo em $43 \%$ a mortalidade na unidade. Em relação a adesão do pacote de $1^{a}$ hora, ainda se mostra extremamente necessário o acompanhamento contínuo da equipe multiprofissional para que as intervenções se tornem mais rápidas e precoces, evitando assim desfechos negativos como deterioração clínica/óbito.

\section{REFERÊNCIAS:}

GONIN, M. L. C. Atualidade na sepse e choque séptico pediátrico. Revista de Pediatria SOPERJ. 2012; 13(2): 77-89.

BRASIL. Instituto Latino Americano de Sepse (ILAS). Campanha de Sobrevivência a sepse - protocolo clínico pediátrico - setembro de 2016. 